\title{
Being And Non-Being: Implication For Conflict Resolution
}

\author{
Francis, Diana-Abasi Ibanga \\ Department of Philosophy, University of Calabar, Cross River State, Nigeria
}

\begin{abstract}
Traditional philosophical problem arises from the distinction between being and non-being, something and nothing, what is and what is not. The objective of this paper is about proving that the distinction can be a framework for conflict resolution, by showing the problem to be a result of misunderstanding of the logical relations of the units. Two study questions are developed to guide the research: (i) what is the nature/structure of the logical relation between being and non-being, and (ii) how does an understanding of that relation feed into conflict and peace discourse. The two research questions are contextualized or articulated under the following conceptual frameworks: (i) Parmenidian disjunctive ontology, and (ii) Heideggerian conjunctive ontology. In conclusion, the paper proves Hedeggerian conjunctive ontology to be adequate framework for negotiation of conflict, by showing conflict to be a result of the Parmenidian error of misunderstanding the logical relation of being and non-being as disjunctive rather than conjunctive.
\end{abstract}

KEYWORDS: Being, Non-being, Parmenides, Heidegger, Ontology, Phenomenology, Conflict.

\section{INTRODUCTION}

In July 1990 the Berlin Wall came tumbling down. The middle wall of partition between capitalist West Germany and socialist East Germany was removed. The collapse of the Berlin Wall was a symbolic precursor of the collapse of the Soviet Union, and a seeming collapse of the bipolar world as it were. The crumbling of the Berlin Wall and Soviet Union was greeted with optimism (in the West) that post-bipolarism would usher in era of peace in the world. The optimism was not unfounded - international relations was basically reduced to the question of what is and what is not, which in turn influenced what was to be allowed. The nuclear arms race that followed was for the purpose of protecting ' what is' against 'what is not' depending on which side of the bipolar world one stood to view the distinction. Typical to all disjunctive bipolarism, an affirmation of 'what is' lead to the denial of 'what is not'. Yet, the paradox was that 'what is' was depending on which side of the bipolar divide one stood. This is the summary of the nuclear arms race, and the wars that were fought. This summary - the question of what is and what is not, of being and non-being - serve to explain the source of the tension between the Christian West and the Muslim Mid-East, and between the North and South. It is also the source of conflict between Sunni and Shiite Muslims.

The issue of being and non-being, what is and what is not, has remained perennial in ontological circles since the time of Parmenides. Every student of philosophy can easily recall that it was Parmenides who first attempted to answer the question of being, ontologically, by asserting that being is and non-being is not. Parmenides insisted that what is or being is that which exist, and that it is one, infinite, unbecoming and indivisible reality (Russell, 2000). That is to say, being is whole, uni-dimensional and static. Since being is and non-being is not, it therefore means that being is truth. Now, because being is unbecoming it follows that it can only be seen the same way always, whereas any claim of contrary view must be viewed as falsity arises from the illusion of the senses. To put it differently, reality can only be viewed the same way always since it is one, indivisible, infinite and static reality. Parmenides further distinguished being and non-being as something and nothing respectively - and called for the liquidation of nothing since it is a mere corruption of the senses or illusion per se.

What does this antagonistic relationship portends for our society? That is, given the metaphysical assertion that being is and non-being is not, what does the world stand to gain or lose from either of them? What dangers, if any, does it pose to our existence? The consideration of the concerns above is the cardinal reference point of this paper - namely, to understanding how the Parmenidian disjunctive approach to the question of being contributes to conflict generation thereby equipping us with the alternative approach to understanding of reality.

\section{HISTORICAL REVIEW OF THE CONCEPTIONS} OF BEING AND NON-BEING

As Unah (2005) rightly notes the study of being earnestly started with the problematic Parmenidian thesis that being is and non-being is not. Although the search for the universal, the essence of phenomena, the 
being of beings historically began with the Thalesian cosmologic thesis that water is the underlying principles of phenomena; it became a problem during the philosophic era of Parmenides and Heraclitus.

Heraclitus had argued that being is always in a perpetual state of flux (Lawhead, 2002). Parmenides retorted: being is one, changeless, eternal and indivisible, and that anything which fail to conform to that layout is a nonbeing, nothing, illusion and false; that since being is what is, anything that exist must come out of it but if it does not come out of being then it is a non-being, nothing and what is not (Stumpf, 1994). This grandstanding therefore set the stage for tension, crisis, conflict and chaos in the society. Whatever did not fit into what was accepted as what is, was repudiated as nothing - hence began the struggle between being and non-being.

The struggle between being and non-being continued to the time of Plato, who described being (that is, what is) as ideas in the world of forms, and phenomena, sensible things, (that is, what is not) as mere shadows and reflections of what is (Stumpf, 1994). Aristotle was to come and brought down the essences of things, the ideas, the forms, the being of beings from their cosmological height but he put it inside the phenomena (Lawhead, 2002. So the being of beings was no longer the platonic alienated type which lied outside the phenomena but became Aristotle's potency or potentiality which lied inside the phenomenon. Every phenomenon has the potentiality of becoming something different, that is, every what is has the potency to become what is not and vice versa. In other words, every being is imbued with the innate ability to become non-being - so by moving from potency to act the non-being asserts itself as being. This became the first attempt to reform being which was consummated in Heidegger's existential phenomenology.

In the $17^{\text {th }}$ century, Leibniz returned to the problem of being with the thesis: "Why is there something instead of nothing?" (Unah, 2006: 3) In an attempt to tackle this question, the German Idealists came in the $19^{\text {th }}$ century to argue that being, that is, what is, is a synthesis of being and non-being. For example, the materialist argues that only matter is what is, being or something and that ideas is what is not, non-being or nothing; of which the idealist retorted that reverse is rather the case. Tension and conflict ensued. Hegel, a representative of the German Idealism, was to come clad in the apparel of Kant, and argued that indeed there is the opposite of being and non-being but there is also a becoming (Okoro, 2008). In other words, Hegel accepted matter, which had been identified by the materialist as the only true reality, the what is, the being or the something, as the thesis; but argued that matter, the what is, being or something would soon be negated by the opposite idea, what is not, non-being or nothing, of which he described as the antithesis.

Hegel argued that the strife between matter and idea, what is and what is not, being and on-being, something and nothing is not an end in itself but must lead to synthesis, becoming, being as such (Okoro, 2008). The concept of synthesis is a clear indication that neither being nor non-being was supplanted; rather they negate each other only to become one - hence there is diversity in unity and unity in diversity, many in one and one in many. Note that by negating each other, they extinguished each other, in other words, both became nothing but became something in each other - the being as such. In other words, the negation of $\mathrm{X}$ by $\mathrm{Y}$ makes $\mathrm{X}$ to become nothing, a non-being and asserts $\mathrm{Y}$ as being $(Y-X=Y)$; but a counter-negation of $\mathrm{Y}$ by $\mathrm{X}$ equally liquidated $\mathrm{Y}$ to nothing, a non-being and assert $\mathrm{X}$ as being $(X-Y=X)$; hence $\mathrm{X}$, like $\mathrm{Y}$, is both being and nonbeing. But Hegel argues that both $\mathrm{X}$ and $\mathrm{Y}$ must become one in $\mathrm{XY}$, not in $\mathrm{Z}$. The $\mathrm{XY}$ means it is a synthesis.

$\begin{array}{lllll}X & + & Y & & X Y \\ X & \pm & Y & \neq & Z\end{array}$

By becoming $\mathrm{XY}, \mathrm{X}$ and $\mathrm{Y}$ became nothing. In other words, $\mathrm{X}$ and $\mathrm{Y}$ has to lose their individual freedoms, that is, negate their being to find freedom or to assert their being in XY. This is how the Hegelian logic attempted to reconcile being and non-being. Hence, Schopenhauer (2002) wrote:

The fundamental mistake of all systems is the failure to recognize this truth, namely that the intellect and matter [being and non-being] are correlatives, in other words, the one exist only for the other; both stand and fall together; the one is only the other's reflex. They are in fact really one and the same thing, considered from two opposite point of view (p.114).

In the 20th century, Martin Heidegger and Jean-Paul Sartre began again the search for being, phenomenologically and existentially respectively and correlatively. Heidegger in particular felt that the question of being had been forgotten, hence the need to raise it anew; in which he asked, "do we in our time have an answer to the question of what we really mean by the word 'being'?" Heidegger's answer was simple: being is still an unresolved problem.

To solve the problem of being, Heidegger turned to phenomenology: for as he argued only phenomenologically an understanding of being is possible (Lawhead, 2002). By proceeding to study being phenomenologically, Heidegger discovered that being is not a fix state of affairs, a fix object of sorts of which fixed and definite characteristics can be ascribed, but a reservoir of inexhaustible possibilities and becoming (Heidegger, 2000). This landed him in the abyss of nothingness or non-being: where being is in a state of potency and becoming only as non-being or nothing. When being, which existed as nothing or non-being, reveal, manifest or show itself in light it becomes regarded as becoming, a being whereas prior to its manifestation it was nonetheless a being. Allegorically, what Heidegger meant is like someone (that is, being) 
standing in the dark, while he stood there in the dark he was regarded as nothing (that is, non-being) because the dark covering made it impossible for him to been seen; but suddenly light shines upon him or he walks into the open, he will be regarded as a person (that is, being) whereas while he was not seen he was still a person (that is, being). But if he disappears back to the dark covering he becomes again non-being though being. Suppose the person (being) reappears with different apparel he would still be recognized as the person although appearing differently.

The allegory dramatizes what Heidegger discovered. Heidegger realized that being is one thing seen differently. Hence in Heidegger Parmenides is affirm 'being is one and timeless and does not change in nature'; and Heraclitus is also upheld 'being reveal itself in profiles (flux)' - in other words, being does not change but only its mode of appearing. Being mode of appearing is like state of flux of which it seems to rise from nothing to something and back to nothing; whereas whether being exists as something or nothing it is nonetheless being. Heidegger was to ground his ontology (treatise on being) on existential-phenomenology which led him to identify being with man. He said: "the being that exist is man". Yet the man is Dasein (being there) but this Dasien is also a transcendent being - the transcendence enable him to negate things and himself (Heidegger, 2000). In fact, man does not negate phenomenon but only negate himself; for that which he seek to negate is that which exist in his subjective mind, his experience which formed in him, in his mind as ideas according to the categories of his mind. Therefore by negating the existing state of affairs he sought to impose a new structure upon it.

Yet the new structure which he seeks to impose on nature does not lie outside nature but in the nothingness. This means man must transcend into nothingness to obtain that which he seek to impose upon nature. But where lays the realm of nothing of which things comes into being: is it outside nature, some alienated place far removed from space and time? Yes, it is a place far removed from space and times. It lies in man in the human subjective reason. It is called the realm of nothingness because it does not exist in space and time. That is where ideas are fabricated, where armies are subdued, where inventions are made. So in transcendence man does not transcend nature but his being to his being. Non-being does not lie outside the subject - esse est percippi. Non-being is the being of man. Okoro (2011) argues "human reality carries nothingness within itself; man is the being through whom nothingness comes into the world; the being by whom nothingness comes into the world must be its own nothingness" (p.47). This is the summary of the trend in the search for being.

\section{BEING AND NON-BEING: AS SOURCE OF CONFLICT}

From the analysis above, we see in the Milean School how being was identified with elements in universe. During the era of Parmenides and Heraclitus, the problem of being shifted to the question permanence and change. In Plato being was split into being and non-being with non-being left in nature and being put outside nature, in the world forms; and Aristotle had to bring it down, put it back into phenomena in nature. In the medieval era being was split again into being (God) and non-being (Satan) but unlike in Plato both being and non-being took residence outside nature far removed from the universe. In the period of German idealism, following the Copernican Revolution, being and non-being was plucked from their cosmological height but rather than put in nature like Aristotle, non-being and being was unified to take residence in human reason. Although Hegel had to objectify it as the Absolute Reason, but Heidegger had to rescue it, de-objectify it and put it back in man.

From the historical analysis above, we can deduce that being, what is, essences, is indeed the problem of philosophy. We can also deduce that the traditional western ontology which runs all the way from Parmenides cannot make meaningful sense if treatment of being is not counter-balanced with non-being. As Schopenhauer (2002) observed both belong together, they cannot be separated; a liquidation of non-being is a liquidation of being since being exist in non-being and vice versa. Therefore, an effort to liquidate non-being on the account of being is a wrong trajectory for the discourse on being to go since non-being lies in being. To this end, there is need to redirect the trajectory of the discourse on being on its right orbit. But how? First, we begun our task concerning the true meaning of being by revisiting the old Parmenidian thesis: being is, non-being is not.

However, the Parmenidian treatment of being has resulted in the fragmentation of being into definite entities. Hence, the question: what is being? The answers were rigid and categorized: being is number, being is matter, being is idea, being is water, being is air, being is atom, being is God, being is Will, being is this, being is that, and so on: Whereas all these are aspects of being and not the whole of being. Unah (2005) notes that "an aspect of being is a fragment of being or a moment of being, not the whole of being" (p.9). Therefore, by magnifying an aspect of being as all that there is, traditional ontology objectified being thereby introducing rigidity, tension and conflict into the world of ideas and people.

Thus, the practice of magnifying an aspect of reality as the totality of reality, the practice of expanding an aspect of being and insisting that it is the whole of being or 
being itself has created confusion... a world of rigidity, inflexibility, inelasticity, creates room for contest and conquest and attitude of vengeance (Unah, 2005:9).

In treating aspect of being as the whole of being or being itself, things become objectified and endowed with fix attributes that are perceptible which definite statements can be referred, for example, being is idea, being is matter, and so on.

What we have done here is to reduce being to a being. And having thus turned being, a process, into a being, an entity, we are prevented in advance from saying something different about it, else one would be charged of uttering something heretical.... This mode of thinking creates the problem of rigidity, inflexibility and inelasticity. Thought become stiff... the systems we create from our thinking, would be straight jacketed, and alternative view points and thoughts would be intolerable... and that those who think differently are in error and must be dealt with decisively, then a stage set for contest and conquest and the resultant attitudes of vengeance and war. This is so because those who see reality differently would want to insist on their position (Unah, 2005:11).

All these happen because "being is and non-being is not". Hence, the Hegelian assertion: "What is, is right". Competition ensues for dominance between being and non-being hypothesizes as what is and what is not. So to be is to contest, conquer and dominate for by conquest and dominance you affirm your being. In this respect, Thrasymacus asserted: "might is right". This is how crisis was introduced into the world.

\section{APPLICATION OF DISCOURSE TO CONFLICT RESOLUTION}

We can see that the Parmenidian disjunctive ontology is the source of conflict in the world because it does not show being in its true light. Now, how then should being be seen or understood. To access being in its true light, Heidegger maintains we should do so phenomenologically - for only as phenomenon does being reveal itself. Unah (2005) avers that "a phenomenon or a thing means that which shows itself, that which display itself, that which leaves itself open for sighting" (p.17). But being, thing or phenomenon has the capacity to show itself differently. This means that being manifest itself in profiles, in various ways and not in a localize state of affairs. Since being only manifest itself phenomenologically we therefore need a phenomenological attitude in approaching being.

A phenomenological approach to being means purging your consciousness of prejudices; which in turns open you up to what manifest. Note that what manifest show itself only as it is, hence, phenomenological orientation enables you to get into the inside of things to their being. When getting into the inside of beings you get to their being, nothingness, from whence they derive their power and meaning. At that stage, the binary, the dichotomy, between being and non-being evaporates - for in being lies non-being. Here conflicts are resolved, armies are dismissed, tensions are quietened and intolerance breaks into laughter of self-folly. Having discovered the true path to being - which is phenomenology - let us now make effort to use the templates as a vehicle for conflict resolution.

What is Conflict? How does it arise? How can it be resolved? Conflict is a state of chaos resulting from tension between two or more antagonistic opposites. From this definition we can assert that conflict does not arise if there is no tension, and tension can only assert itself if there are opposing influences in contest. However, for the purpose of this work I limit scope of the concept of conflict to human relations.

Man is a being-in-the-world which makes him a being-with-others. By this conception, man then is not a being in isolation. Unah and Osegenwune (2010) rightly note: "As man is constituted by his project and his relations with the things which he uses and modifies as implements for realizing them, so is he related to others who are also beings-in-the-world in the same manner as himself" (p.91). However, man must relate with fellow man according to the constitution of his consciousness and experience; whereas the fact of subjectivity has deprived the fellow man of homogeneity in the constitution of his experience and consciousness, hence, man is force to relate from differential experiential standpoints.

The rigid individual rather than appreciate the fact of subjectivity of the other, seek to impose his experience on the other by supplanting his experience with his own. This act prompts resistance or countermeasure, hence tension between them. The rigid man believes that the manner in which phenomena appear in his experiences is the only true version of how it ought to appear to others. The rigid man forgets that human reality is not a given but is only a bundle of possibilities embedded in his experience constituted subjectively by his consciousness. The rigid man being a product of the old Parmenidian orientation introduces crisis into the world through his acts of rigidity, inflexibility, inelasticity and intolerance resulting from his misguided understanding of being.

The question that agitates us now is: how can we get ourselves out of his depraved situation where tension, conflict and crisis are order of the day? As Unah Osegenwune (2010) rightly told us, "it is the duty of philosophy to point the way... to show that there is philosophical basis for tolerance" (p.117). And the way to do this is to urge on phenomenology which is one of the best suited approaches to the liquidation of conflicts. 
Meanwhile, phenomenology is a science or a method of seeing things with an unbiased mindset, open without prejudice and presuppositions (Lawhead, 2002). The phenomenologist sees things clearly from a pre-subjudiced position brushing aside his interest, opinion, judgment, presupposition and any preconceived notion about the thing he engages. By so doing the phenomenological subject gets into the inside of the object of his experience, in other words, he transcends his being to their being. He does not lay claim to certain innate knowledge about his object of encounter; rather he becomes a novice, and naïve before his object of thought, eager to learn. By shedding off his preconceptions and presupposition the man with the phenomenological orientation breed tolerance in the society.

In the light of the explanation above, phenomenological culture can be construed as a basis for tolerance and global peace. Unah and Osegenwune (2010) note that "it marks a radical departure from the archaic Greek epistemology which suggest that readily must be one and that only a single isolated knowing subject could comprehend the totality of experience" (p.119). To this end therefore, the infrastructure of our curriculum should be re-jigged to reflect this new orientation thereby engendering attitude of tolerance in the members of the society. This attitude of tolerance is technically called phenomenological orientation.

In addition to that, phenomenological spirit is a multi-dimensional way of perception. It stresses multiculturalism, multi-representation, multi-forms and multi-vocation. Unah and Osegenwune (2010) argues that phenomenology enable us to recognize "that reality is multi-dimensional and that whatever we perceive of it at any point in time is only a moment of the whole temporal process" (p.118). In other words, phenomenological method is non-impositional approach to issues, discourse and experience. Phenomenology urges attitude of live let live, of equality thereby entrenching human dignity and enhancing opportunities by opening up the world to communication and access by all people; by so doing, it liquidates attitude of fanaticism and intolerance. Phenomenological orientation "demands for all people of all age, cultures and sexes to have unfettered access to discourse or to achieve legitimacy through temporal consensus or dissensus or through relational nonimpositional and non-dogmatic modes of expression" (Unah \& Osegenwune, 2010:167).

All cultural systems are driven by their metaphysical systems which in turn influence the people encapsulated within that culture. Nazism, the driving force of the $2^{\text {nd }}$ World War, was a product of the myth of Rombaden embedded in the German culture. The myth of Rombaden actively negates phenomenological orientation. By injecting douses of phenomenological spirit into our cultural orientation it would lead to multiculturalism, and upstage the world to stand a fair chance of sanity.

\section{CONCLUSION}

We can see, from the discourse above, that any mention of being simultaneously connotes non-being and vice versa. We cannot successful initiate a discussion of being without simultaneously initiating the question of non-being and vice versa. A discussion of being necessarily ends up in non-being, and a discourse on non-being nonetheless dovetails into being. Hence, Schopenhauer avers that both stands and falls together.

Apart from that, we have also seen that the Parmenidian conception of being sort to exclude non-being; but since being and non-being is a necessary part of each other, the Parmenidian vocation to expel non-being, threw the world into confusion and crisis of all sorts. The house of being (the world) became fragile because its foundation (non-being) was neglected. To turn the situation around, I have recommended a new orientation, phenomenology, as the science for the new age when fanaticism and intolerance shall be liquidated.

Finally, I adopt the position of Jim Unah (2006): that an orientation in phenomenology of being can afford us the virtues of prudence, commitment, courage, honesty, confidence, tolerance, listening, dignity, innovation, cooperation, peace, love, patience, altruism, circumspection and moral probity. Above all, it shall open you up to endless and inexhaustible vistas of opportunities and possibilities that lies lantern in nothingness viz. your subconscious self.

\section{REFERENCES}

[1] Heidegger, M. (2000): Introduction to Metaphysics. Trans. Gregory Fried \& Richard Polt (Eds.). New Haven: Yale University Press.

[2] Lawhead, W.F. (2002): The Voyage of Discovery: A Historical Introduction to Philosophy. Belmont: Wadsworth Group.

[3] Okoro, C. (2008): "Philosophy of History as a Theory of Cognition" in Chiedozie Okoro (Ed.) Essays in Epistemology and Philosophy of History. Lagos: Soladem Printers Ltd.

[4] Okoro, C. (2011): "Problems of Philosophy and Metaphysics" in Ephraim-Stephen Essien (Ed.) Summa Philosophica: An Introduction to Philosophy and Logic. Raleigh: Lulu Press.

[5] Russell, B. (2000): History of Western Philosophy. London: Routledge.

[6] Schopenhauer, A. (2002): "The World as Will and Idea" (select.) in Brooke Moore and Kenneth Bruder (Eds.) Philosophy: The Power of Ideas. New York: McGraw Hill Higher Education.

[7] Stumpf, S.E. (1994): Philosophy: History and Problems. New York: McGraw Hill, Inc. 
[8] Unah, J. \& Osegenwune, C. (2010): Phenomenology and Existentialism. Lagos: Fadec Publishers.

[9] Unah, J.I. (2005): On Being: Discourse on the Ontology of Man. Lagos: Fadec Publishers.

[10] Unah, J.I. (2006): Even Nothing is Something. University of Lagos Inaugural Lecture Series. Lagos: University of Lagos Press. 